\title{
Heuristic decision making in network linking
}

Citation for published version (APA):

Harmsen - van Hout, M. J. W., Dellaert, B. G. C., \& Herings, P. J. J. (2016). Heuristic decision making in network linking. European Journal of Operational Research, 251(1), 158-170.

https://doi.org/10.1016/j.ejor.2015.10.039

Document status and date:

Published: 16/05/2016

DOI:

10.1016/j.ejor.2015.10.039

Document Version:

Publisher's PDF, also known as Version of record

Document license:

Taverne

Please check the document version of this publication:

- A submitted manuscript is the version of the article upon submission and before peer-review. There can be important differences between the submitted version and the official published version of record.

People interested in the research are advised to contact the author for the final version of the publication, or visit the DOI to the publisher's website.

- The final author version and the galley proof are versions of the publication after peer review.

- The final published version features the final layout of the paper including the volume, issue and page numbers.

Link to publication

\footnotetext{
General rights rights.

- You may freely distribute the URL identifying the publication in the public portal. please follow below link for the End User Agreement:

www.umlib.nl/taverne-license

Take down policy

If you believe that this document breaches copyright please contact us at:

repository@maastrichtuniversity.nl

providing details and we will investigate your claim.
}

Copyright and moral rights for the publications made accessible in the public portal are retained by the authors and/or other copyright owners and it is a condition of accessing publications that users recognise and abide by the legal requirements associated with these

- Users may download and print one copy of any publication from the public portal for the purpose of private study or research.

- You may not further distribute the material or use it for any profit-making activity or commercial gain

If the publication is distributed under the terms of Article $25 \mathrm{fa}$ of the Dutch Copyright Act, indicated by the "Taverne" license above, 


\title{
Heuristic decision making in network linking
}

\author{
Marjolein J. W. Harmsen - van Hout ${ }^{\mathrm{a}, *}$, Benedict G. C. Dellaert ${ }^{\mathrm{b}, 1}$, P. Jean-Jacques Herings ${ }^{\mathrm{c}, 2}$ \\ ${ }^{a}$ Institute for Future Energy Consumer Needs and Behavior (FCN), School of Business and Economics / E.ON Energy Research Center, RWTH Aachen University, \\ Mathieustraße 10, Aachen, 52074 Germany \\ ${ }^{\mathrm{b}}$ Department of Business Economics / Marketing Section, Erasmus School of Economics, Erasmus University Rotterdam, P.O. Box 1738, Rotterdam, 3000 DR The \\ Netherlands \\ ${ }^{\mathrm{c}}$ Department of Economics, Maastricht University, P.O. Box 616, Maastricht, 6200 MD The Netherlands
}

\section{A R T I C L E I N F O}

\section{Article history:}

Received 2 January 2015

Accepted 19 October 2015

Available online 24 October 2015

\section{Keywords:}

Network formation

Individual decision making

Heuristic effects

Laboratory experiment

Mixed logit

\begin{abstract}
A B S T R A C T
Network formation among individuals constitutes an important part of many OR processes, but relatively little is known about how individuals make their linking decisions in networks. This article provides an investigation of heuristic effects in individual linking decisions for network formation in an incentivized labexperimental setting. Our mixed logit analysis demonstrates that the inherent complexity of the network linking setting causes individuals' choices to be systematically less guided by payoff but more guided by simpler heuristic decision cues, and that this shift is systematically stronger for social payoff than for own payoff. Furthermore, we show that the specific complexity factors value transferability and social tradeoff aggravate the former effect. These heuristic effects have important research and policy implications in areas that involve network formation.
\end{abstract}

(c) 2015 Elsevier B.V. All rights reserved.

\section{Introduction}

Network formation among individuals has important effects in many social, operational, and economic contexts, ranging from wordof-mouth communications among consumers (e.g., Iacobucci \& Hopkins, 1992) and virtual communities (e.g., Wellman et al., 1996) to job opportunities (e.g., Granovetter, 1995) and mortality (e.g., Berkman \& Syme, 1979). Therefore, the OR community has lately modeled such decentral network creation processes (e.g., Baron, Durieu, Haller, \& Solal, 2006; Demaine, Hajiaghayi, Mahini, \& Zadimoghaddam, 2012; Fabrikant, Luthra, Maneva, Papadimitriou, \& Shenker, 2003; Harmsen - van Hout, Herings, \& Dellaert, 2013; Hellmann \& Staudigl, 2014; Janssen \& Monsuur, 2012; Monsuur, 2007; Olaizola \& Valenciano, 2014). The applications of these models vary from military and other communication networks to large-scale networking settings as the Internet and their approaches differ from non-cooperative and cooperative game theory to structural optimization mechanisms.

In the current paper, we comply with the recent call by Hämäläinen, Luoma, and Saarinen (2013) to explicitly consider behavioral phenomena within OR processes, as these processes are

\footnotetext{
* Corresponding author. Tel.: +49 24180 49835; fax: +49 2418049829 .

E-mail addresses: mharmsen@eonerc.rwth-aachen.de (M.J.W. Harmsen - van Hout),dellaert@ese.eur.nl (B.G.C. Dellaert), p.herings@maastrichtuniversity.nl (P.J.J. Herings)

1 Tel.: +31 104081 353; fax: +31 104089169 .

2 Tel.: +31433883 824, +31433883 636; fax: +31 433884878 .
}

highly sensitive to behavioral effects. Accordingly, the abovementioned OR models on decentral network creation may result in opposite recommendations for optimal interventions. Although the approaches of these models vary in several respects, they all take optimizing individuals as a starting point, at most with some random deviation therefrom (e.g., Baron et al., 2006; Hellmann \& Staudigl, 2014), whereas we investigate in how far real people systematically deviate from this assumption.

There exists a recent and increasing experimental literature on network formation. One stream in this literature is involved with testing integral game-theoretic models of network formation. They include variants of Bala and Goyal's (2000) noncooperative network formation model (e.g., Berninghaus, Ehrhart, \& Ott, 2006; Callander \& Plott, 2005), Jackson and Wolinsky's (1996) pairwise cooperative network formation model (e.g., Deck \& Johnson, 2004), and fully cooperative network formation models like Jackson and van den Nouweland's (2005) (e.g., Charness \& Jackson, 2007). This research identifies several conditions under which theoretically stable network structures are reproduced in the laboratory and addresses their efficiency. Another stream of experimental studies examines the role of network formation as endogenously emerging in other relevant settings of cooperative decision making (e.g., Brown, Falk, \& Fehr, 2004; Corbae \& Duffy, 2008; Di Cagno \& Sciubba, 2010; Hauk \& Nagel, 2001; Kirchsteiger, Niederle, \& Potters, 2005). This research shows that cooperation decisions are considerably influenced when individuals are allowed to choose their partners versus when a fixed interaction structure is imposed. Furthermore, Falk and Kosfeld 
(2012), Goeree, Riedl, and Ule (2008), and van Dolder and Buskens (2014) found social motives in network formation.

From this experimental work it became clear that in extremely complex, dynamic and strategic situations, predictions of network formation models are not always accurate. An issue that has been largely ignored in this previous work though is that the complexity that individuals face in network formation may moderate their decisions already on a much more basic level. Also disregarding dynamics and strategic interaction, the network formation process is typically a complex decision setting, for individuals' utilities are not only dependent on multiple characteristics of the choice options, like in most consumer choices (e.g., Swait \& Adamowicz, 2001), and even not only additionally on the number of other individuals choosing the same option, like with global network externalities (e.g., Katz \& Shapiro, 1985). They depend on all individuals in the entire pattern of network links, differently by their exact positions (e.g., Sundararajan, 2008). Furthermore, this network complexity varies depending on whether the type of value that is exchanged through the network only affects direct neighbors or is rather transferable via indirect links (Harmsen - van Hout et al., 2013) and depending on whether decision makers care about the effects of their choices on other individuals (Fehr \& Schmidt, 2003).

Such complexity may cause errors in their evaluation of different link formation options and hence in their choice process. Although previous research acknowledges the mere existence of errors (e.g., Charness \& Jackson, 2007), these are simply modeled as random and the underlying process remains undisclosed. In fact, the complexity causing such errors is typically removed by providing experimental subjects with numerical payoff information in the network linking choice interfaces. The objective of the current paper is to investigate whether systematic heuristic shifts occur in individual decision making in network formation as a function of complexity in the network linking setting. Such complexity effects have been studied in several other choice contexts (e.g., Bonner, 1994; Dellaert, Donkers, \& Soest, 2012; Sung, Johnson, \& Dror, 2009; Timmermans, 1993).

For this purpose, we focus on a static, non-strategic network setting in which the decision maker can choose to create or delete one link or to do nothing. Such a situation constitutes the simplest network linking decision context, which allows us to study the effects of complexity under highly controlled conditions. To prevent possible confounding effects that do not originate from complexity of the network setting but from strategic interaction among individuals, we thus analyze individual one-period decisions, so decisions of others in the network are deliberately excluded.

A typical decision task as we study is as follows. The individual "you" in Fig. 1 is connected with several other individuals in a network and is facing the one-shot choice problem to change at most one link: her choice options are to delete one of her existing links, so with "a" or "d", to create a link with one individual that she is currently not directly connected to, so "b" or "c", or not to change anything. This results in a new network structure that generates value for "you" as well as for "a" through "d", whereas "a" through "d" do not make any changes to the network.

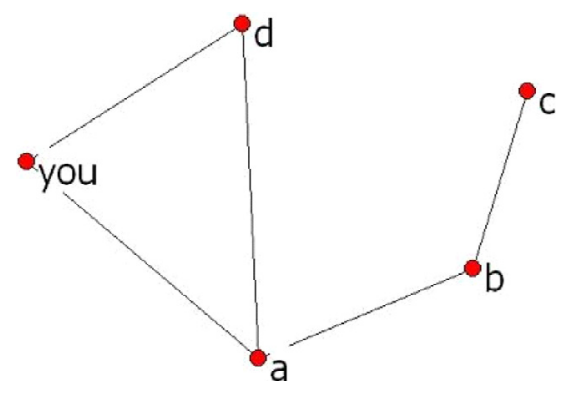

Fig. 1. Example network formation setting.
In this individual decision-making experiment we vary three complexity factors that are relevant in the context of network linking. The first factor is baseline opacity of choice consequences. We induce this by providing participants in some treatments with a comprehensive payoff table, which is an effective way to systematically reduce complexity. The second factor is transferability of value over the network. We induce this by having participants in some treatments derive value from direct neighbors only, which reflects a situation where social value is derived from communication, and having participants in other treatments derive value from direct as well as indirectly connected individuals, which reflects a situation where informational value is derived from communication. The third factor is social tradeoff between own payoff and others' payoff. We induce this by informing participants in some treatments that nobody else was affected by their choices, and informing participants in other treatments that the other participants in the room would be passively affected by their choices in a specific way.

These factors complicate the choices that individuals make about creating and maintaining links in the network. We examine whether these choices therefore become systematically less payoff-motivated but more guided by simpler heuristic decision cues, and furthermore whether this shift to heuristic cues is systematically stronger for the extent that individuals' choices are guided by social payoff, that is, the payoff generated for other individuals, than for the extent they are guided by own payoff.

In order to test our hypotheses, we confront participants in the lab with multiple linking choice situations similar to the one in Fig. 1. Their choices have a direct impact on their monetary rewards in the experiment, which differ with respect to the three abovementioned complexity factors (baseline payoff opacity, value transferability, social tradeoff), leading to different treatments. We perform a comprehensive parametric test of the hypotheses by estimating a mixed (i.e., random parameters) logit model (Hensher, Rose, \& Greene, 2005; McFadden, 2001) incorporating several payoff and decision cue variables as well as their interactions with the complexity factors. This allows us to investigate the impact of complex network properties on individuals' decisions, while allowing for heterogeneity of the decision makers.

Using this approach, we identify two cues that are merely qualitatively related to payoff but appear to have a significant additive impact on linking decisions: whether the choice option implies a deviation from the status quo or not, and the number of direct neighbors of the (potential) linking partner involved in the choice option. The effects of these heuristic cues are different under the various complexity factors. Furthermore, we demonstrate that social preferences throughout strongly rely on a numerical overview of choice consequences (which is usually provided in the laboratory but missing in real life), since apparent pro-social decision behavior in treatments with such an overview disappears in identical treatments without.

In Section 2, we present our theoretical framework and hypotheses. Section 3 describes the experimental design and the approach used for the mixed logit estimation. The results of our experiment and hypotheses tests are reported in Section 4. At the end of this section, we perform several robustness checks, among which whether observed shifts in behavior may as well be captured by differences in randomness among complexity conditions. Section 5 concludes the paper with a discussion including implications for OR decentral network creation modeling.

\section{Theoretical framework}

The objective of this section is to present our hypotheses about heuristic effects in individual decisions of network formation and compare them to predictions on individual choice behavior underlying the previous experimental network formation literature. 
The predictions based on prior theories are reviewed in Section 2.1 and our hypotheses are presented in Section 2.2.

\subsection{Prior decision models}

Economic theory (e.g., Varian, 1992, chap. 7) models experienced utility, that is, utility on which actual decisions are based, as follows. The experienced utility that individual $i$ derives from choosing option $j$ is given by:

$U_{j}^{i}=f^{i}\left(\right.$ Payoff $\left._{j}\right)$,

where Payoff $j$ is the payoff, that is, benefits minus costs, obtained by $i$ when she chooses $j$ and $f^{i}$ is a strictly increasing function. For empirical applications, a random factor can be added (e.g., Hensher et al., 2005, chap. 3$)$ :

$U_{j}^{i}=f^{i}\left(\right.$ Payoff $\left._{j}\right)+\varepsilon_{j}^{i}$.

We refer to this as the classical payoff-based model. For the example of Fig. 1, this model predicts that from the five choice options allowed, "you" chooses an option that provides her with the highest payoff.

Social preferences theory (Fehr \& Schmidt, 2003) augments this model by explicitly allowing for the fact that in addition to their own payoff, individuals may take the payoff for other individuals into account when making their decisions. In this case, the experienced utility that individual $i$ derives from choosing option $j$ is given by:

$U_{j}^{i}=f^{i}\left(\right.$ OwnPayoff $\left._{j},\left(\text { OthersPayoff }{ }_{j}^{h}\right)_{h \neq i}\right)+\varepsilon_{j}^{i}$,

where OwnPayoff $f_{j}$ is the payoff personally obtained by $i$ when she chooses $j$, OthersPayoff ${ }_{j}^{h}$ is the payoff obtained by another individual $h$ when $i$ chooses $j$, and $f^{i}$ is a function reflecting how $i$ holds othersguided utility components in mind (e.g., inequity aversion, efficiency preferences, etc.). We refer to this as the classical payoff-based model extended with social preferences. For the example of Fig. 1, this model predicts that from the five choice options allowed, "you" chooses an option that causes her subjectively optimal combination of payoff for herself and payoff for the four other individuals.

\subsection{Hypotheses}

Our anticipation is that these prior utility models are not sufficient to explain link choice behavior due to the presence of a specific type of complexity. This complexity arises due to local network effects: an individual's payoff from her own choice now is affected by all individuals in the entire pattern of network links, differently by their exact positions (e.g., Sundararajan, 2008). Therefore, she finds it an inherently complex task to determine the precise payoff of linking choice options.

As humans are boundedly rational (Camerer, 1998), they cope with complexity in decision making by simplification, which commonly involves assessing a judgment object (e.g., linking choice option) using only the subset of properties of the object that are most accessible, that is, that come most readily to mind, rather than using all relevant properties (Gigerenzer, Todd, \& the ABC research Group, 1999), as long as this leads them to a satisfying situation (Simon, 1956). This is clearly illustrated in the literature about the effects of task complexity in several other contexts, like job candidate selection (Timmermans, 1993), audit judgment (Bonner, 1994), consumer choice (Dellaert et al., 2012; Swait \& Adamowicz, 2001), and betting markets (Sung et al., 2009), but no empirical research to date has addressed such effects in making complex network formation decisions.

We propose two main types of heuristic shifts: (i) the complexity in the network linking setting makes individuals' choices systematically less payoff-guided than predicted by the classical payoff-based model in that they are additionally motivated by other heuristic cues (Section 2.2.1) and (ii) it makes them deviate from the predictions of the classical payoff-based model extended with social preferences in being systematically less socially motivated (Section 2.2.2). Furthermore, we examine whether these effects are stronger under more complex linking decision making conditions, where we vary the presence of value transferability and social tradeoff (Section 2.2.3).

\subsubsection{Payoff orientation}

In the network formation setting, the decision maker's payoff depends on the network structure after completion of her choice, where having more connections is on the one hand beneficial, since they provide access to additional resources, and on the other hand costly, for it takes time and effort to maintain them. Because of network effects, it is typically a complex task for individuals to judge the exact payoff consequences of link choice options and we examine whether therefore individuals systematically deviate from payoff orientation.

A psychological process of judgment simplification is encountered in the literature about conjunctive probability assessment, which shows that individuals make predictions based on a correlation they assume to exist between the assessment variable and some other variable (e.g., Broniarczyk \& Alba, 1994). Accordingly, individuals could partly substitute the payoff value of a link choice option by descriptive attributes that can be determined more easily and that are qualitatively related to it. Consequently, they could shift their orientation from exact payoff to the most basic cues (i) whether a link choice option involves actively deleting or creating a link or rather doing nothing (Kahneman, Knetsch, and Thaler (1991) describe how the status quo is a predisposed option for decision makers), and (ii) how many direct links the individual involved in the choice option has in the network (Freeman (1979) describes how the degree of a node is the most basic indicator of centrality, which in turn is the most basic social network measure). This is in line with qualitative process theory, which suggests that human reasoning is more likely to depend on qualitative rather than quantitative relations (Forbus, 1993). Therefore, in our model we allow for individuals' use of the type of action or individual as simpler heuristic cues in addition to the precise expected payoff.

We hypothesize:

H1 (reduction of payoff orientation): Individuals' network linking choices are affected less strongly by their payoff consequences than predicted by the classical payoff-based model (Section 2.1) in that they are also systematically based on heuristic cues.

Pursuing the above line of reasoning, we formulate the experienced utility that individual $i$ may derive from choosing option $j$ with the following heuristic cues:

$U_{j}^{i}=f^{i}\left(\right.$ Payoff $_{j}$, Complexity $\times\left(\right.$ Payoff $_{j}$, Formation $_{j}$, Degree $\left.\left._{j}\right)\right)+\varepsilon_{j}^{i}$,

where Complexity is the network choice complexity that $i$ is facing, Formation $_{j}$ is a dummy variable indicating by zero that $j$ involves remaining with the status quo and by one that it involves link deletion or creation, Degree $_{j}$ is the number of direct links of an individual with whom $i$ deletes or creates a link in $j$, and $f^{i}$ is a function increasing in Payoff $f_{j}$ and decreasing in the interaction of Complexity with Payoff $f_{j}$. For the example of Fig. 1, this model predicts that from the five choice options allowed, "you" chooses one that seems to provide her with the highest payoff, which she partly bases on the simple cues (i) whether the option implies a deviation from the status quo (which is the case for four options) and (ii) the degree of the node involved in the option (which varies between zero and three among options) rather than on the quantitative amount. Since several qualitative relations exist between the heuristic cues and payoff, we do not predict the signs of their net effects. 


\subsubsection{Social preferences}

The presence of social tradeoff is a further complicating factor in the network setting, implying that an individual's choices not only affect her own value, but also the value for her neighbors, her neighbors' neighbors, etc. (e.g., Bala \& Goyal, 2000; Jackson \& Wolinsky, 1996). This aspect of network formation choices makes it more complex for individuals with social preferences to judge the exact value of link choice options, because besides their own payoff they also have to consider the payoff of other individuals.

We investigate whether individuals deal with the complexity of social tradeoff by focusing on the payoff aspect that can be determined most easily (Gigerenzer et al., 1999), that is, own payoff. Therefore, we examine whether individuals tend to pay systematically less attention to others' payoff due to the greater complexity of evaluating this social payoff. In the past, behavioral economists have found empirical evidence for social preferences. Recently, Falk and Kosfeld (2012), Goeree et al. (2008), and van Dolder and Buskens (2014) found social motives in network formation, but this was in lab environments where choice complexity was largely mitigated by explicit payoff information, which directly presented participants with the numerical payoff consequences for themselves as well as for others of their choice options. We expect a smaller influence of payoff consequences for other individuals on choice when this is not the case. Obviously, since payoff for another individual is at least as opaque as own payoff, we anticipate a baseline shift from payoff to heuristic cues as predicted by $\mathrm{H} 1$ also for social payoff. However, we additionally expect a systematic heuristic shift from others' to own payoff when complexity is not artificially removed. This shift may be both due to a concious shift of consideration from social to own payoff and due to an unintended stronger shift to the use of heuristic cues for social payoff. Thus, we propose the following hypothesis:

H2 (reduction of social preferences): Individuals' network linking choices are affected less strongly by their payoff consequences for other individuals than predicted by the classical payoff-based model extended with social preferences (Section 2.1) in that complexity systematically reduces the impact of social payoff on these choices more strongly than the impact of own payoff.

We include this heuristic effect in the experienced utility that individual $i$ derives from choosing option $j$ as follows:

$$
\begin{aligned}
U_{j}^{i}= & f^{i}\left(\text { OwnPayoff }_{j},\left(\text { OthersPayoff }_{j}^{h}\right)_{h \neq i},\right. \text { Complexity } \\
& \left.\times\left(\text { OwnPayoff }_{j},\left(\text { OthersPayoff }_{j}^{h}\right)_{h \neq i}, \text { Formation }_{j}, \text { Degree }_{j}\right)\right),
\end{aligned}
$$

where $f^{i}$ is a function decreasing in the interaction of Complexity with (OthersPayoff $\left.f^{h}\right)_{h \neq i}$. For the example of Fig. 1, this model predicts that from the five choice options allowed, "you" chooses one that seems to cause her subjectively optimal combination of payoff for herself and payoff for the other individuals, where we expect the latter payoff to get systematically less attention due to complexity.

\subsubsection{Reinforcing complexity conditions}

Finally, we hypothesize that in addition to the baseline opacity of choice consequences in this context due to the fact that network externalities have to be taken into account, two specific complexity aspects of networks may strengthen individuals' tendencies to switch from payoff to heuristic cues orientation and to reduce their social preferences.

Value transferability. The first network factor regarded here is value transferability, which refers to the fact that an individual derives value not only from her direct neighbors, but also indirectly from her neighbors' neighbors, etc. This network property makes it even more complex for individuals to judge the exact payoff of link choice options, because it requires additional cognitive work to be forwardlooking over indirect links. This leads to the following hypotheses:

\section{H3 (moderating effects of value transferability):}

H3a: The presence of value transferability in a network decreases the impact of payoff on an individual's link formation choices in that it systematically increases the impact of heuristic cues.

$\mathrm{H} 3 \mathrm{~b}$ : The presence of value transferability in a network decreases the impact of others' payoff on an individual's link formation choices systematically more strongly than the impact of own payoff.

Social tradeoff. Another complexity property we consider is social tradeoff, implying that an individual's choices not only affect her own value, but also the value for her neighbors, her neighbors' neighbors, etc. (cf. Section 2.2.2). This network property makes it more complex for individuals with social preferences to judge the exact value of link choice options, because besides their own payoff they have to consider the payoff of (possibly many) other individuals, which requires extra cognitive effort. Therefore, the presence of social tradeoff will not only cause a shift of preferences from others' to own payoff $(\mathrm{H} 2)$, but we also expect it to have a strengthening effect on their shift from payoff to heuristic cues orientation. This can be formulated in the following hypothesis:

H4 (moderating effect of social tradeoff): The presence of social tradeoff in a network decreases the impact of payoff on an individual's link formation choices in that it systematically increases the impact of heuristic cues.

We include these moderating effects of complexity factors in the experienced utility that individual $i$ derives from choosing option $j$ as follows:

$$
\begin{aligned}
U_{j}^{i}= & f^{i}\left(\text { OwnPayoff }_{j},\left(\text { OthersPayoff }_{j}^{h}\right)_{h \neq i},\right. \text { ComplexityCondition } \\
& \left.\times\left(\text { OwnPayoff }_{j},\left(\text { OthersPayoff }_{j}^{h}\right)_{h \neq i}, \text { Formation }_{j}, \text { Degree }_{j}\right)\right),
\end{aligned}
$$

where ComplexityCondition is the network choice complexity condition that $i$ is facing - concerning both the baseline opacity of choice consequences due to network externalities and the reinforcing complexity of value transferability and social tradeoff - and $f^{i}$ is a function in which the hypothesized interaction effects with ComplexityCondition are included. For the example of Fig. 1, this model predicts that from the five choice options allowed, "you" chooses one that seems to cause her subjectively optimal combination of payoff for herself and payoff for the other individuals, which systematically varies with the complexity condition.

\section{Methods}

In this section we describe the experimental design as well as the parametric approach used for testing our hypotheses.

\subsection{Experimental design}

Our experiment presented participants with six network formation link choice problems similar to that in Fig. 1. In these problems a participant was allowed to change at most one direct link, that is, to delete a link that already exists between her and another individual, to create a link between her and another individual if there is not yet one, or to change nothing. The choice problems are illustrated in Tables A.1 (1-3) and A.2 (4-6), Appendix A. They were created such that they represent a variety of network linking decisions while enabling mutual comparison. The number of individuals as well as the total number of links was kept constant in all six choice problems. 
Table 1

Experimental design.

\begin{tabular}{llll}
\hline & \multicolumn{2}{l}{ Social tradeoff } \\
\cline { 2 - 3 } & & NO & YES \\
\hline Value & NO & none & social (part 1, part 2) \\
transferability & YES & transfer & both (part 1, part 2) \\
\hline
\end{tabular}

Pilot studies conducted by the authors before the experiment indicated that most other structural complexity factors like the number of visual crossings between links did not affect participants' choices. An exception was whether the decision maker was connected to the rest of the network at the moment of choice or not. Therefore, three of the six choice problems involved a connected position and the other three an isolated position for the participant. Furthermore, to avoid unanticipated biases due to other structural factors, the order of choice problems was rotated among participants.

To test for the hypothesized shifts in behavior due to value transferability and social tradeoff, we employed four experimental treatments where these two characteristics were between-subjects factors. Thus, each participant faced one of four particular complexity conditions (see Section 2.2.3). The experimental design is summarized in Table 1. Parts 1 and 2 for the treatments social and both refer to a within-subject manipulation that will be discussed later in this section.

Each participant was confronted with a payoff function matching her treatment. This function reflects the benefits and costs of link formation according to a typical situation in communication networks with high cost of link specificity as modeled by Harmsen - van Hout et al. (2013). The more direct connections an individual has to maintain with other individuals, the less she is able to specify her attention per link. Therefore, her value per link for others declines and she also derives less value from each link with others. Two connected agents contribute to their bilateral process of communication value creation according to a standard Cobb-Douglas production function with as inputs the amount of time invested by each agent in the link. High link specificity implies unit output elasticities in each bilateral value production process and therefore low advantage of being connected with several others. The respective payoff function was explained in words to the participants in the instructions.

For a participant $i$ in treatment none or social there was no value transferability, so value was derived from direct neighbors only. This reflects a situation where social value is derived from communication (Harmsen - van Hout et al., 2013). The payoff function was then given by:

$$
\Pi_{i}=\left\{\begin{array}{cc}
\sum_{j \in N_{i}} \frac{1}{\mu_{i} \mu_{j}} & \text { if } \mu_{i}>0 \\
0 & \text { if } \quad \mu_{i}=0
\end{array}\right.
$$

where $N_{i}$ is the set of individuals with whom $i$ has a direct link, individual $j$ is a neighbor of $i$ if $j \in N_{i}$, and $\mu_{i}=\left|N_{i}\right|$ is the number of neighbors of $i$, that is, the degree of $i$. In the instructions, this payoff function was presented by the following elementary verbal description: "For each node you are directly linked with (we call such a node a neighbour) you obtain points. However, there is also some cost associated with being connected: the number of points you receive for each of your direct neighbours equals 10 divided by two components: (i) the number of direct neighbours you have, and (ii) the number of direct neighbours this neighbour has", supplemented with an elaborated numerical example (see the Supplementary material, Appendix C).

For treatments transfer and both there was value transferability, so value was derived from direct as well as indirectly connected individuals. This reflects a situation where informational value is derived from communication (Harmsen - van Hout et al., 2013). The payoff function was then given by:

$$
\Pi_{i}=\left\{\begin{array}{cc}
\sum_{j \in \bar{N}_{i}} \sum_{p \in \mathcal{P}_{i, j}} \frac{1}{\mu_{i} \mu_{j} \prod_{k \in \breve{p}}\left(\mu_{k}\right)^{2}} & \text { if } \mu_{i}>0 \\
0 & \text { if } \mu_{i}=0,
\end{array}\right.
$$

where $\bar{N}_{i}$ is the set of individuals with whom $i$ has either a direct or an indirect link, $\mathcal{P}_{i, j}$ is the set of paths between $i$ and $j$, where a path is defined as a sequence of consecutive links without repeated individuals, $\breve{p}$ is the set of individuals on path $p$ between $i$ and $j$ excluding $i$ and $j$ themselves, and $\mu_{i}$ is the degree of $i$. In the instructions, this payoff function was formulated as "For each path that links you to some other node you obtain points. However, there is also some cost associated with being connected: the number of points you receive for each path that links you to some other node equals 10 divided by three components: (i) the number of direct neighbours you have in the network, (ii) the number of direct neighbours this other node has in the network, and (iii) the square of the number of direct neighbours that any of the further nodes on the path between you and the other node has in the network" and illustrated by an example (see the Supplementary material, Appendix C).

For treatments none and transfer there was no social tradeoff. The participants were informed that nobody else was affected by their choices. For treatments social and both there was social tradeoff. The participants were informed that the other individuals in the choice problems were not reflecting real people with the ability to influence their payoff, that the payoff their choices generated for these fictive individuals were determined analogously to their own payoff, and that the total payoff their choices generated for these fictive individuals would be divided equally among the other participants in the room. Thus, a simple form of social preferences, not involving distributional issues, was evoked.

It can be checked that the six choice problems introduced above are selected such that they each provide the opportunity to explicitly reveal social preferences in both the treatments with and without value transferability. For example, in choice problem 5 (as visualized with options' respective payoffs in Table 2), in the treatments without value transferability, participants can exhibit social preferences in the sense that while keeping their own payoff at its maximum they can choose better or worse for the others (e.g., by selecting option d versus option c), and in the treatments with value transferability, participants can exhibit social preferences in the sense that by giving up some of their own payoff they can improve the payoff for others (e.g., again by selecting option d versus option c). The payoffs for the other choice problems are given in Table A.3 in Appendix A. No information or feedback about the tasks and choices of the other participants was provided during the experiment in order to ensure that strategic motivations are absent.

To control for individual differences in social preferences, for participants in treatments social and both where payoff for other participants had to be considered, an additional part was added to the experiment. This was exactly the same as the first part, but for each choice option the payoff for the participant as well as for the others was mentioned explicitly. This is illustrated in Fig. 2. Charness, Fréchette, and Kagel (2004) and Gürerk and Selten (2012) showed that providing participants with such a comprehensive payoff table is an effective way to systematically reduce complexity. The objective of this extra manipulation was to test in how far participants take others' payoff into account when the complexity of doing so is practically removed. Thus, for the treatments social and both, whether or not numerical payoff information was provided was incorporated as a within-subjects factor. Note that for the treatments without social tradeoff, it is obvious that participants would always choose optimally when provided with a payoff overview, so we do not bother them with such a second part.

The experiment took place in a computer lab with students and employees of various faculties of Maastricht University, the 
Table 2

Payoffs choice problem 5.

Value transferability NO $\quad$\begin{tabular}{l} 
Value transferability YES \\
\hline
\end{tabular}

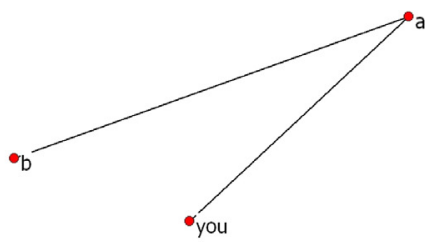

What do you choose?

D I do nothing. This means that I earn 5 points and 15 points will be divided equally among the other participants in this room.

C I delete the link with a. This means that I earn 0 points and 20 points will be divided equally among the other participants in this room.

D I create a link with $b$. This means that I earn 5 points and 10 points will be divided equally among the other participants in this room.

Fig. 2. Illustration payoff information.

Netherlands. The 48 male and 66 female participants from diverse nationalities were randomly assigned to the four between-subject treatments. Thus, the number of independent observations is larger than common in the existing experimental network formation literature, e.g., Di Cagno and Sciubba (2010) run only six sessions (with six interdependent participants each) per treatment. Participants were informed how the payoffs they would earn in the experiment would be converted into cash euros afterwards, see the Supplementary material (Appendix C) for details. After each choice, feedback was given to the participant about the payoff she earned for herself and if relevant for the other participants in the room, and the respective maximum and minimum payoffs that could have been earned in the specific choice problem. Participants could only start the experiment after answering a number of control questions correctly to make sure the instructions were understood correctly and after two really paid-out practice rounds with only three choice options, see Table A.4, Appendix A. Our pilot experiments already increasingly confirmed that the instructions were generally understood after working through the example. At the end of the experiment participants were asked to comment on their motives and the way they made their choices in a debriefing part. Average earnings were $€ 6.03$.

\subsection{Mixed logit estimation}

We perform a comprehensive parametric test of our hypotheses by estimating a mixed (i.e., random parameters) logit model (Hensher et al., 2005). This estimation approach enables us to establish the roles of several attributes of link options in the network formation process, while allowing for heterogeneity across individuals. The total potential experienced utility that individual $i$ under treatment $t$ derives from choosing option $j$ in choice problem $c$ is affected by both payoff and other factors as well as the complexity treatment she is facing, and is formalized as follows:

$$
\begin{aligned}
U_{c j}^{t i}= & \sum_{k \in K} \beta_{k}^{i} P_{k c j}^{t}+\sum_{m \in M} \gamma_{m}^{i} C_{m c j}+\sum_{k \in K} \varphi_{k} T^{t} P_{k c j}^{t}+\sum_{m \in M} \chi_{m} T^{t} C_{m c j} \\
& +\theta S^{t} P_{1 c j}^{t}+\sum_{m \in M} \xi_{m} S^{t} C_{m c j}+\zeta T^{t} S^{t} P_{1 c j}^{t}+\sum_{m \in M} \eta_{m} T^{t} S^{t} C_{m c j} \\
& +\sum_{k \in K} \psi_{1 k} I_{c}^{t} P_{k c j}^{t}+\sum_{m \in M} \psi_{2 m} I_{c}^{t} C_{m c j}+\sum_{k \in K} \psi_{3 k} I_{c}^{t} T^{t} P_{k c j}^{t} \\
& +\sum_{m \in M} \psi_{4 m} I_{c}^{t} T^{t} C_{m c j}+\varepsilon_{c j}^{t i}
\end{aligned}
$$

where

$K \quad$ is the set of payoff indices $\{1,2\}$,

$P_{1 c j}^{t} \quad$ is the own payoff generated under $t$ when in $c$ she chooses $j$,

$P_{2 c j}^{t} \quad$ is the payoff generated for the other participants,

$M \quad$ is the set of decision cue indices $\{1,2\}$,

$C_{1 c j}$ is a cue dummy variable indicating deviation from the status quo,

$C_{2 c j} \quad$ is a cue variable indicating the number of direct links of an individual with whom a link is deleted or created,

$T^{t} \quad$ is a dummy variable indicating the presence of value transferability, that is, treatment transfer or both,

$S^{t} \quad$ is a dummy variable indicating the presence of social tradeoff, that is, treatment social or both,

$I_{c}^{t} \quad$ is a dummy variable indicating the presence of numerical payoff information (within-subject manipulation), and

$\varepsilon_{c j}^{t i} \quad$ is a stochastic variable drawn from a standard Gumbel distribution.

Notice that interactions between $S$ and $P_{2}$ or between $S, T$ and $P_{2}$ do not provide additional information to $P_{2}$ or the interaction between $T$ and $P_{2}$ respectively and therefore are not included, and that interactions including both $I$ and $S$ do not provide additional information to interactions only including $S$ and therefore are not incorporated either. Interactions among payoff and decision cue factors (e.g., between $P_{1}$ and $C_{2}$ ) are not included due to lack of interpretability. 
Table 3

Descriptive results choice problem 5 .

\begin{tabular}{lclc}
\hline none & \multicolumn{3}{l}{ transfer } \\
\hline Choice & $\%$ & Choice & $\%$ \\
nothing & 43.3 & nothing & 17.9 \\
a & 0.0 & a & 0.0 \\
b & 40.0 & b & 60.7 \\
c & 10.0 & c & 7.1 \\
d & 3.3 & d & 0.0 \\
e & 0.0 & e & 3.6 \\
f & 3.3 & f & 10.7 \\
\hline \multirow{2}{*}{ social / payoff info NO } & social / payoff info YES \\
\hline Choice & $\%$ & Choice & $\%$ \\
nothing & 10.7 & nothing & 53.6 \\
a & 0.0 & a & 0.0 \\
b & 39.3 & b & 21.4 \\
c & 7.1 & c & 7.1 \\
d & 17.9 & d & 7.1 \\
e & 0.0 & e & 3.6 \\
f & 25.0 & f & 7.1 \\
\hline both / payoff info NO & both / payoff info YES \\
\hline Choice & $\%$ & Choice & $\%$ \\
nothing & 35.7 & nothing & 25.0 \\
a & 0.0 & a & 0.0 \\
b & 28.6 & b & 46.4 \\
c & 7.1 & c & 25.0 \\
d & & e & 3.6 \\
e & & f & 0.0 \\
f & & & \\
\hline & & & \\
\hline
\end{tabular}

In random parameter $\beta_{k}^{i}$, superscript $i$ allows for heterogeneity due to individuals' personal preferences as follows:

$\beta_{k}^{i}=\beta_{k}+v_{k}^{i}$,

where $v_{k}^{i}$ is a stochastic variable drawn from a normal distribution. Analogously, random parameters are included for the baseline effects of the decision cue variables on choice $\left(\gamma_{m}^{i}\right)$.

Then, under the usual assumptions, the unconditional probability that individual $i$ will choose option $j$ equals the expected value of the logit probability over all possible values of the random parameters. Given the nature of our experimental design as described in Section 3.1, complete orthogonality of all regressors in the logit model is not possible, but all correlations between payoffs and heuristic cues as well as between own and others' payoffs are below 0.31 . The model is estimated by Maximum Likelihood with NLOGIT 5.0, Econometric Software, Inc., implementing 1000 Halton draws in the Monte Carlo simulation.

\section{Results}

\subsection{Illustrative descriptive results}

Before turning to a more formal analysis, we first present some illustrative results for the choices made in the different treatments. Hereby the focus is first on choice problem 5 (Table 2), of which Table 3 gives the choice percentages in the different treatments.

In treatment none (first row Table 3), without value transferability and social tradeoff, all participants choose one of the optimal options, that is, nothing, b, c, d, or f. However, in treatment transfer, where value transferability is included, only $67.8 \%$ of the respective participants chooses one of the optimal options, that is, b or c. This is in line with H3a. Comparing none to transfer, the percentage of participants choosing to maintain the status quo decreases from 43.3 to 17.9 , and linking to $b$, which has a degree of one only, becomes even more popular. This complies with the heuristic cues introduced in Section 2.2.1 for $H 1$.
Table 4

Optimal choice in the complexity treatments.

\begin{tabular}{|c|c|c|c|c|}
\hline & & \multicolumn{3}{|c|}{ Social tradeoff } \\
\hline & & NO & $\begin{array}{l}\text { YES, without } \\
\text { payoff info }\end{array}$ & $\begin{array}{l}\text { YES, with } \\
\text { payoff info }\end{array}$ \\
\hline Value & NO & $97 \%$ & $89 \%$ & $96 \%$ \\
\hline transferability & YES & $47 \%$ & $45 \%$ & $78 \%$ \\
\hline
\end{tabular}

Table 5

Social preferences in the complexity treatments.

\begin{tabular}{|c|c|c|c|c|c|}
\hline & & \multicolumn{4}{|l|}{ Social tradeoff } \\
\hline & & \multicolumn{2}{|l|}{ YES, without payoff info } & \multicolumn{2}{|l|}{ YES, with payoff info } \\
\hline \multirow{3}{*}{$\begin{array}{l}\text { Value } \\
\text { transferability }\end{array}$} & NO & $\begin{array}{l}\text { max others | max own } \\
\text { Pareto inferior }\end{array}$ & $\begin{array}{l}27 \% \\
11 \%\end{array}$ & $\begin{array}{l}\text { max others | max own } \\
\text { Pareto inferior }\end{array}$ & $\begin{array}{r}58 \% \\
4 \%\end{array}$ \\
\hline & YES & max others $\mid \max$ own & $39 \%$ & max others $\mid \max$ own & $73 \%$ \\
\hline & & Pareto inferior & $30 \%$ & Pareto inferior & $7 \%$ \\
\hline
\end{tabular}

In treatment social (second row Table 3), where social tradeoff is included, while keeping own payoff optimal, one can maximize the payoff for others by choosing to change nothing. Only $10.7 \%$ of the respective participants turns out to opt for this, though all these participants still maximize their own payoff, that is, select option nothing, $b$, $c$, d, or f. However, in the second part of the experiment, when payoff information is given, thus eliminating complexity, $53.6 \%$ of the same participants prefers this option. This pattern corresponds to $\mathrm{H} 2$. Note that changing nothing maintains the status quo, which again relates to one of the heuristic cues.

In treatment both (third row Table 3), with both value transferability and social tradeoff, only $42.9 \%$ of the respective participants chooses one of the options with optimal own payoff, that is, b or c, whereas the rest seems to be willing to give up some of their own payoff in order to improve the payoff for others. Note that $21.3 \%$ even chooses a Pareto inferior option, that is, a, d, e, or f. However, in the second part of the experiment, when payoff information is given, thus eliminating complexity, the proportion with optimal own payoff increases to $71.4 \%$. Also, only $3.6 \%$ chooses a Pareto inferior option. This result is in line with $H 4$. Notice that the option to link to e, which has the relatively high degree of three, remains impopular in all treatments, which is in accordance with one of the heuristic cues once more.

In Table 4 an overview across all choice problems is provided of how often participants choose optimally in the different treatments and in Table 5 of how often participants maximized other participants' payoff given own maximal payoff and how often they choose a Pareto inferior option in the sense that both own and others' payoff could be strictly improved by choosing a different option. The tables confirm that participants were more effective in optimization the less complex the treatment.

In Table 6 we count frequencies of how often participants remained with the status quo in the three choice problems where the decision maker is not isolated, as in the three choice problems with an isolated start position, remaining with the status quo is consistently very bad for payoff and was chosen accordingly rarely in all treatments. Prominent differences appear in the treatments with social tradeoff: in social without payoff information, the percentage of status quo choices is considerably lower than in social with payoff information (and even lower than when each of the seven choice options would have been chosen with equal probability), whereas in both without payoff information, the percentage of status quo choices is considerably higher than in both with payoff information. In Table 7 the average degree of the nodes involved in the chosen options across all problems is listed. With random choice, the average degree would be 1.31 , and with a random selection of one of the options that provide optimal own payoff, the average degree would be 0.98 and 1.06 
Table 6

Remaining with the connected status quo in the complexity treatments.

\begin{tabular}{|c|c|c|c|c|}
\hline & & \multicolumn{3}{|c|}{ Social tradeoff } \\
\hline & & NO & $\begin{array}{l}\text { YES, without } \\
\text { payoff info }\end{array}$ & $\begin{array}{l}\text { YES, with } \\
\text { payoff info }\end{array}$ \\
\hline Value & NO & $24 \%$ & $11 \%$ & $36 \%$ \\
\hline transferability & YES & $21 \%$ & $24 \%$ & $14 \%$ \\
\hline
\end{tabular}

Table 7

Average degree of the nodes involved in the chosen options in the complexity treatments.

\begin{tabular}{lllll}
\hline & & \multicolumn{2}{l}{ Social tradeoff } \\
\cline { 3 - 5 } & NO & $\begin{array}{l}\text { YES, without } \\
\text { payoff info }\end{array}$ & $\begin{array}{l}\text { YES, with } \\
\text { payoff info }\end{array}$ \\
\hline Value & NO & 0.83 & 0.96 & 0.90 \\
transferability & YES & 1.36 & 1.26 & 1.00 \\
\hline
\end{tabular}

without and with value transferability respectively. Thus, in treatment none participants over-selected low-degree options and in the treatments with value transferability (and no payoff overview) participants over-selected high-degree options.

The above crosstab results are in line with our hypotheses, but cannot be interpreted as direct evidence, since alternative explanations for differences between choice frequencies in the treatments are possible. For example, it could be that all differences in complexity just lead to differences in choice precision, implying that allowing for conditional random error terms in network formation modeling would be sufficient, whereas we hypothesize more systematic changes in decision making. Also, even though we restricted our focus to the very simple setting of a static, non-strategic network in which the decision maker can choose to create or delete one link or to do nothing, it could be that confounding effects play a role, for instance, the exact payoffs in the treatments with value transferability are by definition different from those in the treatments without (although the order of magnitude of these differences is relatively small). In the mixed logit approach in the next section these alternative explanations can be accounted for. Namely, confounding effects are dealt with by the comprehensiveness of the model itself, where for example both exact payoffs and simple heuristic cues are included as explanatory variables. Explicit comparison to shifts in randomness is made in the last robustness check of Section 4.2.2.
Notice that we did not hypothesize that the payoff derived from heuristic network linking decisions would be far from optimal. In fact, across all choice problems, participants earned a fraction of 0.9 from the own payoffs they could have earned in the treatments social part 1, transfer, and both part 1, and even 0.99 in the treatment none, whereas pure random selection would only have led to a proportion of 0.8 from the own payoffs that could have been earned. So in that sense, if heuristics were used, they may be considered rather "smart" (cf. Gigerenzer et al., 1999).

Further descriptive results, primarily from the debriefing part, are given in Appendix B.

\subsection{Mixed logit results}

A comprehensive parametric test of the hypotheses is conducted by estimating a mixed logit model across all treatments (Section 4.2.1). A p-value of 0.05 is taken as cut-off value for significance. In Section 4.2.2 several robustness checks are performed.

\subsubsection{Hypothesized model}

The estimation results for all experimental treatments including the interaction effects of an explicit payoff overview are given in Table 8.

In these results we find support for the reduction of payoff orientation in this complex setting (H1), since besides the own payoff, the degree of the individual involved in the choice option appears to be significantly influential on a linking decision, where individuals with many links are avoided in comparison with relatively isolated individuals (negative $\gamma_{2}^{i}$ ). This might be based on the qualitative notion that maintaining links is costly. For the treatments with social payoff, where the within-subjects factor of numerical payoff information was included, this is reconfirmed by the positively significant $\psi_{11}$-coefficient, indicating that when participants were provided with such a comprehensive payoff overview, the impact of payoff on their linking choices increased.

With respect to the expected reduction of social preferences in the network formation context ( $\mathrm{H} 2)$, we find strong confirmation as the $\beta_{2}^{i}$-coefficient is not significant at all, whereas in the situation where participants were provided with numerical payoff information, the corresponding coefficient $\left(\psi_{12}\right)$ is positively significant, showing that the same individuals were more willing to consider the consequences of their choices for others than they actually did in the first round

Table 8

Mixed logit estimations.

\begin{tabular}{|c|c|c|c|c|}
\hline Variable & Parameter & $\begin{array}{l}\text { Estimated mean } \\
\text { ( } p \text {-value })\end{array}$ & $\begin{array}{l}\text { Estimated stand. } \\
\text { dev. ( } p \text {-value) }\end{array}$ & Cf. hypothesis \\
\hline own payoff & $\beta_{1}^{i}$ & $1.814(0.000)$ & $0.476(0.000)$ & \\
\hline others' payoff & $\beta_{2}^{i}$ & $-0.014(0.732)$ & $0.135(0.000)$ & 2 \\
\hline formation & $\gamma_{1}^{i}$ & $0.501(0.232)$ & $1.023(0.000)$ & 1 \\
\hline degree & $\gamma_{2}^{i}$ & $-0.848(0.000)$ & $0.165(0.252)$ & 1 \\
\hline transferability * own payoff & $\varphi_{1}$ & $-1.075(0.002)$ & & 3 \\
\hline transferability * others' payoff & $\varphi_{3}$ & $-0.022(0.689)$ & & 3 \\
\hline transferability $*$ formation & $\chi_{1}$ & $-1.456(0.012)$ & & 3 \\
\hline transferability * degree & $\chi_{2}$ & $1.500(0.000)$ & & 3 \\
\hline social tradeoff * own payoff & $\theta_{1}$ & $-1.133(0.001)$ & & 4 \\
\hline social tradeoff $*$ formation & $\xi_{1}$ & $1.444(0.039)$ & & 4 \\
\hline social tradeoff $*$ degree & $\xi_{2}$ & $-0.117(0.723)$ & & 4 \\
\hline transferability $*$ social tradeoff * own payoff & $\zeta$ & $1.261(0.002)$ & & \\
\hline transferability ${ }^{*}$ social tradeoff* formation & $\eta_{1}$ & $-1.450(0.117)$ & & \\
\hline transferability $*$ social tradeoff * degree & $\eta_{2}$ & $0.034(0.930)$ & & \\
\hline payoff info * own payoff & $\psi_{11}$ & $0.872(0.002)$ & & 1 \\
\hline payoff info * others' payoff & $\psi_{12}$ & $0.136(0.004)$ & & 2 \\
\hline payoff info $*$ formation & $\psi_{21}$ & $-1.992(0.009)$ & & \\
\hline payoff info $*$ degree & $\psi_{22}$ & $0.477(0.196)$ & & \\
\hline payoff info * transferability $*$ own payoff & $\psi_{31}$ & $0.518(0.201)$ & & \\
\hline payoff info * transferability * others' payoff & $\psi_{32}$ & $-0.098(0.159)$ & & \\
\hline payoff info $*$ transferability $*$ formation & $\psi_{41}$ & $3.136(0.002)$ & & \\
\hline payoff info $*$ transferability $*$ degree & $\psi_{42}$ & $-0.983(0.044)$ & & \\
\hline
\end{tabular}


of the experiment. Also, this effect is stronger than for own payoff, since in the treatments with social tradeoff, exact own payoff is still considered, as $\left|\theta_{1}\right|<\beta_{1}^{i}$.

The hypothesized moderating effects of value transferability are supported with respect to the reduction of payoff orientation $(\mathrm{H} 3 a)$ : the $\varphi_{1}$-coefficient of the payoff interaction term turns out to be negatively significant. We see that instead, participants stuck significantly more to the status quo (negative $\chi_{1}$ ) and reversed their preference for isolated versus central individuals $\left(\chi_{2}\right)$. The former might be subscribed to the fact that it is now more complex to calculate what it brings to deviate from already satisfying situations, whereas the latter might be due to the qualitative notion that since value is now transferable over indirect links, having more links is more beneficial. Since others' payoff were already completely ignored in the choices of the participants, it is no longer possible for the additional complexity factor value transferability to significantly decrease their effect $(H 3 b)$.

The hypothesized moderating effect of social tradeoff on payoff orientation (H4) is corroborated as well, for the $\theta_{1}$-coefficient is also significantly negative. Here, respondents had the tendency to deviate from the status quo (positive $\xi_{1}$ ). This overactivity might be related to the fact that it is complex to calculate whether situations satisfying with respect to own payoff will be also beneficial for the others now involved, which suggests that some latent social motives are still present, but the situation is too complex to deal with them like in the less complex part with direct payoff information.

Finally, respondents' behavior significantly varies among participants in several respects as can be concluded from the significant random parameter standard deviations in the next to last column of Table 8.

\subsubsection{Robustness}

In this section, we check whether our estimation results are robust for several control variables.

Order effects. The model is re-estimated where additionally interaction terms are included of each of the four main variables (i.e. those with a random parameter) with a control variable tracking the position of the respective option in the list of choice options, to check for robustness against order effects. We find one small but significant order effect: the interaction effect of others' payoff with the order variable is $0.004(0.005)$, indicating that others' payoff becomes systematically slightly more relevant for lower-listed choice options. Importantly, almost all previously found heuristic effects remain. The single exception is the positive interaction effect of social tradeoff with formation $\left(\xi_{1}\right)$, which becomes insignificant now ( $p$-value 0.202). However, the interaction effect of social tradeoff and own payoff $\left(\theta_{1}\right)$ remains significantly negative, indicating that $H 4$ still holds, but suggesting that there is a shift to some heuristic cue left unidentified in the current pioneering model.

Learning effects. The model is re-estimated for the first part of the experiment only (without numerical payoff information) - for the second part of the experiment, when payoff tables are provided to the same participants, it is not straightforward how to extend the definition of the experience variable - where additionally interaction terms are included of each of the four main variables with a control variable measuring experience by tracking how many problems the participant already solved at the respective moment of choice, to check for robustness against learning effects. We find that almost all previously found heuristic effects remain, with the same exception as at the robustness check against order effects described above. It turns out that more experienced individuals have a significantly stronger tendency to avoid individuals with many links, so the heuristic effects in network formation decisions as explored in the current paper are definitely not transitory.
Table 9

Summary experimental results.

\begin{tabular}{ll}
\hline Hypothesis & Result \\
\hline $\begin{array}{l}\text { Heuristic effects of complexity on linking choice } \\
\text { H1: reduction of payoff }\end{array}$ & $\begin{array}{l}\text { supported (low degree as heuristic cue in baseline) } \\
\text { orientation }\end{array}$ \\
$\begin{array}{ll}\text { H2: reduction of social } \\
\text { preferences }\end{array}$ & $\begin{array}{l}\text { supported (numerical payoff necessary to consider } \\
\text { other individuals' payoff at all) }\end{array}$ \\
Moderating effects of specific complexity factors \\
sulue transferability & $\begin{array}{l}\text { supported for reduction of payoff orientation (high } \\
\text { degree and remaining with status quo as heuristic }\end{array}$ \\
& $\begin{array}{l}\text { cues); social preferences could not be further } \\
\text { reduced }\end{array}$ \\
H4: social tradeoff & $\begin{array}{l}\text { supported (deviating from status quo as heuristic } \\
\text { cue) }\end{array}$ \\
\hline
\end{tabular}

Random shift effects. Finally, we compare our model to a more restricted model where instead of including the specific interaction effects for the treatments, we only allow the variance of the error term to linearly depend on them, to check whether differences among treatments as predicted by $\mathrm{H} 2$ through $\mathrm{H} 4$ are possibly merely due to shifts in choice precision (Salisbury \& Feinberg, 2010), so whether more complexity only leads to more randomness. This rival model turns out to perform significantly worse in terms of model fit (the loglikelihood decreases from -1540.872 to -1647.825 ), strengthening our claim of more systematic effects of complexity on link choice behavior.

\section{Discussion}

\subsection{Conclusions}

A concise summary of our results is given in Table 9.

The hypothesis that individuals' network linking choices are affected less strongly by their payoff consequences than predicted by the classical payoff-based model (H1) is supported by the mixed logit estimation of Section 4.2.1, as it indicates that these choices are also based on heuristic cues. Already in the baseline treatment where payoffs are obscured due to network externalities, a lower degree of the node involved in the option significantly explains choice whereas the exact payoff was also included as an explanatory variable. In the treatments with value transferability, higher degrees become significantly more attractive and remaining with the status quo becomes an additional heuristic cue. In the treatments with social tradeoff, we even find a reverse status quo bias, which is quite unique in the literature (cf. Mengel, 2011), but this requires further research as it is not robust against order and learning effects. These results are also reflected in the descriptive Tables 6 and 7 in Section 4.1.

The hypothesis that individuals' network linking choices are affected less strongly by their payoff consequences for other individuals than predicted by the classical payoff-based model extended with social preferences due to a systematic shift of motivation from social to own payoff $(\mathrm{H} 2)$ is strongly supported by the mixed logit estimation, as it indicates that these choices do not merely become more socially motivated when the complexity is largely removed by a comprehensive payoff overview (as reflected in descriptive Table 5 in Section 4.1), but they are even not socially motivated at all without such a numerical table. Indeed, the impact of own payoff on choices does not suffer to this extent from the same level of complexity. Note that some respondent answers in the debriefing part of the experiment suggest that this shift of the impact from social to own payoff as a consequence of social tradeoff is partly due to a concious shift of consideration away from social payoff (Appendix B, item 5). Our explanation of the reverse status quo bias in Section 4.2.1 suggests that it is also partly due to an unintended stronger shift to the use of heuristic cues for social payoff. 
The hypothesized moderating effects of the complexity factors value transferability and social tradeoff $(H 3, H 4)$ are also supported by the mixed logit estimation, as their presence further decreases the impact of payoff on an individual's link formation choices, which is also reflected in descriptive Table 4 in Section 4.1.

Thus, this study shows that complexity in the network formation setting influences individual link choice behavior in a systematic way, since individuals' choices are guided less by payoff, where the attention appears to be shifted to factors only qualitatively related to payoff, and moreover, this effect is stronger for social payoff than for own payoff. Furthermore, we demonstrate that the specific complexity factors value transferability and social tradeoff aggravate the former effect. In Section 4.2.2 (Random shift effects) it was confirmed that these changes in behavior cannot accurately be captured by a model only allowing for differences in choice precision (or randomness) among complexity treatments.

\subsection{Implications}

The current study initiates empirical research into the issue of heuristic effects in individual decisions of network formation. Our results should raise interest in future research into this realm, for they have important implications for theoretical and experimental research as well as application areas of network formation.

Our results show that behavioral effects play a crucial role in the process of decentral network formation. Therefore, theoretical OR models of network creation (e.g., Baron et al., 2006; Demaine et al., 2012; Fabrikant et al., 2003; Harmsen - van Hout et al., 2013; Hellmann \& Staudigl, 2014; Janssen \& Monsuur, 2012; Monsuur, 2007; Olaizola \& Valenciano, 2014) should take such effects into consideration. In particular, the current experiment was based on payoff functions used in Harmsen - van Hout et al. to model communication network formation with high link specificity. This kind of models should not only allow for random error to become more realistic, but should explicitly include human tendencies as found by our analysis to base complex linking decisions on heuristic cues like status quo and node degree rather than exact payoff. As seen in Section 4.1 , the consequences for payoffs in the simplest setting may not be very high, but it may very well be expected that the structural and efficiency predictions and therefore recommendations for interventions resulting from these more complex models differ largely if their agents are no longer optimizing but consider much simpler decision cues instead (cf. Hämäläinen et al., 2013). For example, the model with high link specificity by Harmsen - van Hout et al. predicted a wide range of networks in situations without value transferability, including non-standard networks like highly connected and "small world" networks, and highly fragmented, efficient networks in situations with value transferability. Similarly, predictions were made for other levels of link specificity and several recommendations for network moderation were based hereupon. It should be investigated in how far these still hold with agents behaving heuristically rather than purely optimizing.

On the other hand, our results suggest that the existent network formation models are already correct in not taking social preferences into account, for though previous laboratory research indicated that people do have them, we show that the complex decision environment keeps them from being revealed.

Furthermore, experimental research practice is often disposed to make the payoff consequences of choices as transparent as possible for participants to prevent biased findings due to their wrong understanding of the instructions. However, we claim that this explicit information modifies participants' behavior in a systematic way, since it eliminates complexity that they otherwise would handle by heuristic shifts.
Finally, in many contexts of network formation among individuals such as job opportunities (e.g., Granovetter, 1995) and mortality (e.g., Berkman \& Syme, 1979), it matters to be aware of heuristic effects as found in this study. For example, with word-of-mouth communications among consumers (e.g., Iacobucci \& Hopkins, 1992), for the supplier of the respective product or service it is interesting to know when consumers have a tendency to talk with isolated or central peers and that they neglect benefits that peers derive from their communication decisions. Also, suppliers can exploit the finding that this behavior is dependent on the complexity of the network environment, for example, by facilitating information about social payoffs.

\subsection{Future research}

Diverse linear transformations to convert points earned to euro payments - which we used over complexity conditions to equalize the average monetary rewards with which our participants leave the laboratory - might influence decisions (Maddox, Bohil, \& Dodd, 2003). Although we think it unlikely that participants in our experiment were able to comprehend more than the fact that earning more points would increase their ultimate monetary payoff as well (see the Supplementary material, Appendix C), further work could account for this in another way.

In order to prevent interference of complexity types that are not the focus of the current research, we studied a relatively simple network linking decision that is only one-shot and involves only one active participant changing at most one link. Also, the payoff information is complete and certain. Future research could study whether and in how far additional (and often previously studied) complexity types such as strategic interaction, dynamics, multi-link deviation, incomplete information, and uncertainty strengthen the heuristic effects shown by the current paper.

Furthermore, in this pioneering study we could find significant shifts from exact payoff to the descriptive attributes qualitatively related to it that to the best of our knowledge can be determined most easily by a decision maker, namely remaining with versus deviating from the status quo and the degree centrality of a node. Issues like cognitive distinctions between deleting and creating a link or between connectedness and disconnectedness of the decision maker could be considered in future work, as well as decision cues based on more advanced centrality or other social network measures, e.g., the number of nodes reached at a distance of two. Similarly, follow-up experiments could investigate the effects of demographics and other background variables as collected in Appendix B if explicitly designed to do so.

Another direction that future studies could take concerns the question in how far the complexity types and heuristic effects we considered are specific for the network context. For example, in how far does complexity systematically reduce social preferences in other choice settings? Moreover, further experiments could generate deeper insights in the linking choice process of individuals by concentrating on specific effects from the rich range of heuristic tendencies explored here.

\section{Acknowledgments}

The authors gratefully acknowledge two anonymous referees for their helpful suggestions and constructive comments. The third author would like to thank the Netherlands Organisation for Scientific Research (NWO) Grant no. 453-02-014 for financial support .

\section{Appendix A. Choice problems}


Table A.1

Choice problems 1-3.

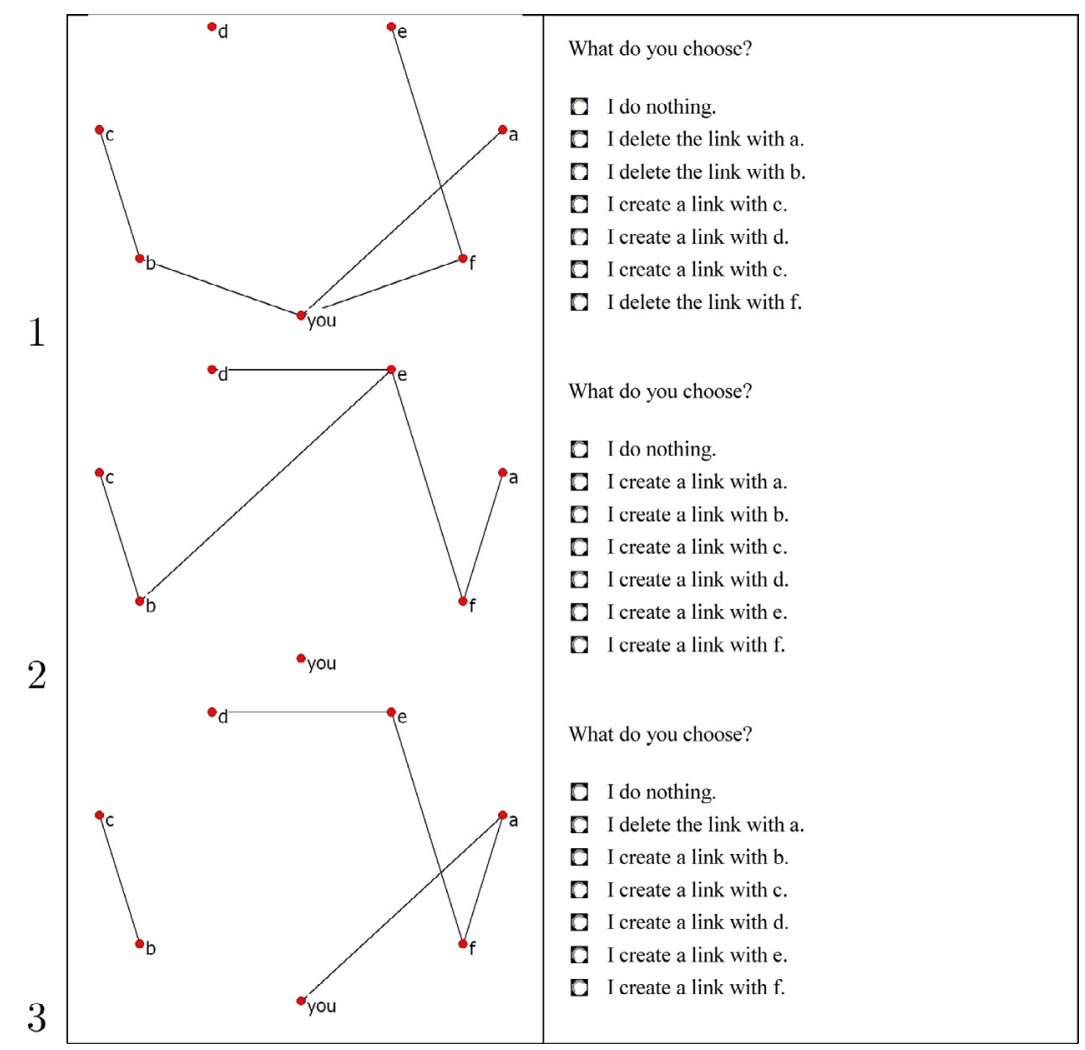

Table A.2

Choice problems 4-6.

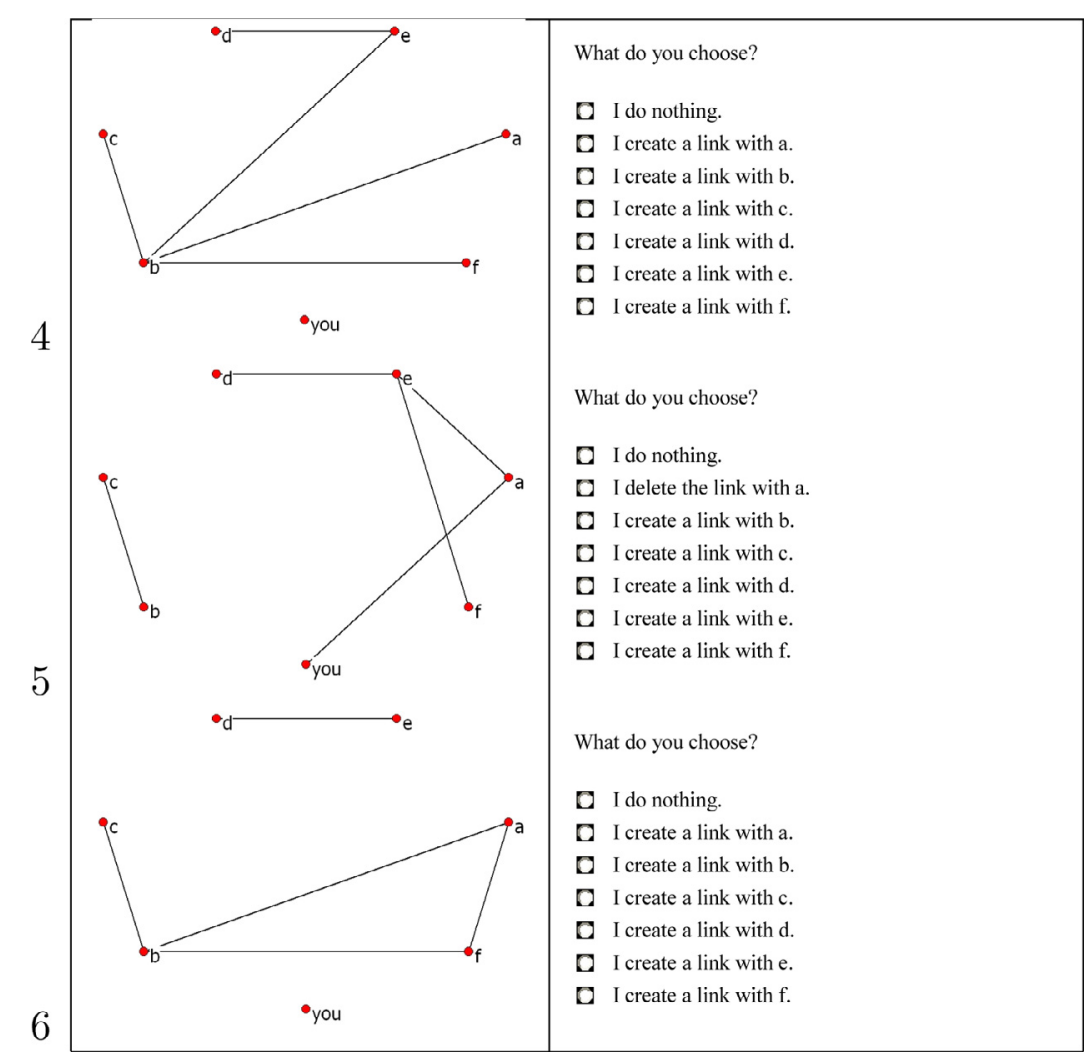


Table A.3

Payoffs choice problems $1-4$ and 6.

\begin{tabular}{|c|c|c|c|c|c|c|}
\hline & \multicolumn{3}{|c|}{ Value transferability NO } & \multicolumn{3}{|c|}{ Value transferability YES } \\
\hline \multirow[t]{8}{*}{1} & & you & others & & you & others \\
\hline & nothing & 6.67 & 26.67 & nothing & 8.33 & 32.92 \\
\hline & $\mathrm{a}$ & 5 & 25 & $\mathrm{a}$ & 7.5 & 30.31 \\
\hline & $\mathrm{b}$ & 7.5 & 37.5 & $\mathrm{~b}$ & 8.75 & 42.5 \\
\hline & c & 6.25 & 21.25 & $\mathrm{c}$ & 7.5 & 26.48 \\
\hline & d & 7.5 & 27.5 & $\mathrm{~d}$ & 8.75 & 34.45 \\
\hline & $\mathrm{e}$ & 6.25 & 21.25 & $\mathrm{e}$ & 7.5 & 26.48 \\
\hline & $\mathrm{f}$ & 7.5 & 37.5 & $\mathrm{f}$ & 8.75 & 42.5 \\
\hline \multirow[t]{8}{*}{2} & & you & others & & you & others \\
\hline & nothing & 0 & 33.33 & nothing & 0 & 41.25 \\
\hline & $\mathrm{a}$ & 5 & 33.33 & $\mathrm{a}$ & 6.58 & 41.51 \\
\hline & $\mathrm{b}$ & 3.33 & 32.22 & $\mathrm{~b}$ & 5.03 & 39.72 \\
\hline & c & 5 & 33.33 & c & 6.58 & 41.51 \\
\hline & $\mathrm{d}$ & 5 & 35 & $\mathrm{~d}$ & 6.25 & 42.5 \\
\hline & $\mathrm{e}$ & 2.5 & 32.5 & $\mathrm{e}$ & 4.06 & 39.14 \\
\hline & $\mathrm{f}$ & 3.33 & 32.22 & $\mathrm{f}$ & 5.03 & 39.72 \\
\hline \multirow[t]{8}{*}{3} & & you & others & & you & others \\
\hline & nothing & 5 & 45 & nothing & 6.72 & 51.09 \\
\hline & $\mathrm{a}$ & 0 & 45 & $\mathrm{a}$ & 0 & 51.25 \\
\hline & b & 5 & 35 & $\mathrm{~b}$ & 7.11 & 44 \\
\hline & c & 5 & 35 & c & 7.11 & 44 \\
\hline & d & 5 & 40 & $\mathrm{~d}$ & 6.64 & 46.56 \\
\hline & $\mathrm{e}$ & 4.17 & 39.17 & e & 5.83 & 44.58 \\
\hline & $\mathrm{f}$ & 4.17 & 40.83 & $\mathrm{f}$ & 5.38 & 45.59 \\
\hline \multirow[t]{8}{*}{4} & & you & others & & you & others \\
\hline & nothing & 0 & 27.5 & nothing & 0 & 35.31 \\
\hline & $\mathrm{a}$ & 5 & 30 & $\mathrm{a}$ & 6.05 & 37.15 \\
\hline & $\mathrm{b}$ & 2 & 26 & $\mathrm{~b}$ & 3.5 & 32.7 \\
\hline & c & 5 & 30 & c & 6.05 & 37.15 \\
\hline & d & 5 & 27.5 & $\mathrm{~d}$ & 6.52 & 35.74 \\
\hline & $\mathrm{e}$ & 3.33 & 26.67 & $\mathrm{e}$ & 4.93 & 34.24 \\
\hline & $\mathrm{f}$ & 5 & 30 & $\mathrm{f}$ & 6.05 & 37.15 \\
\hline \multirow[t]{8}{*}{6} & & you & others & & you & others \\
\hline & nothing & 0 & 38.33 & nothing & 0 & 43.33 \\
\hline & $\mathrm{a}$ & 3.33 & 38.89 & $\mathrm{a}$ & 4.57 & 43.58 \\
\hline & b & 2.5 & 37.5 & $\mathrm{~b}$ & 3.91 & 42.03 \\
\hline & c & 5 & 40 & c & 6.18 & 44.79 \\
\hline & d & 5 & 33.33 & $\mathrm{~d}$ & 7.5 & 40.83 \\
\hline & $\mathrm{e}$ & 5 & 33.33 & $\mathrm{e}$ & 7.5 & 40.83 \\
\hline & $\mathrm{f}$ & 3.33 & 38.89 & $\mathrm{f}$ & 4.57 & 43.58 \\
\hline
\end{tabular}

\section{Appendix B. Descriptive results}

1. Duration: average 40.2 minutes, stand. dev. 14.8 minutes.

2. Almost all participants tried to earn as much as possible, whereas 17 subjects indicated other goals: best choices (6), fun/interest (2), optimal own payoffs and not too bad payoffs for the others (4), optimal own payoffs and minimal payoffs for the others (1), structural goals (4).

3. In the first choice problem (practice round), participants chose as follows: at random: 1 , by calculation: 60 , by intuition: 34 , using a rule: 13 , namely connect to the one with the least neighbors/shortest paths (13), otherwise: 6 , namely mix of intuition and calculation (5), mistake in understanding instructions at first (1).

4. Thereafter, did participants change their strategies? No: 67, for the strategy was good or convenient and the problems were similar, yes: 47 , switch (more) to calculation (12), intuition/experience (22), or rule mentioned in descriptive 3. (11), or consider other participants more (2).

5. In conditions social and both, did participants take into account the points created for other participants? 36 did not, since they didn't think about it (4), didn't care about it (16), didn't know how (5) or didn't like the effort (11), 20 did, where they (conditionally) maximized $(\geq 8)$ or minimized $(\geq 3)$ the points for the others, two participants seem not to understand that dividing among other participants does not include yourself.

6. Strategies in the second part (with numerical payoff information) of conditions social and both: (conditionally) maximizing payoffs for the others (25), choosing not too badly for the others (7), (conditionally) minimizing payoffs for the others (6), trying to repeat first part (8), unclear (10).

7. Strategic considerations in conditions social and both? No: 18 , since they didn't think about it (7), thought that the other participants wouldn't care (5), the other participants are outside control (4), or it would be too difficult (2), yes, but did not influence choices: 9 , yes, hoping for a favorable group: 5 , or expecting an unfavorable group: 2 , yes, unclear how: 22 (at least five of these seem not to understand that this question is about the others creating points for you and not about you creating points for the others).

Table A.4

Practice rounds.

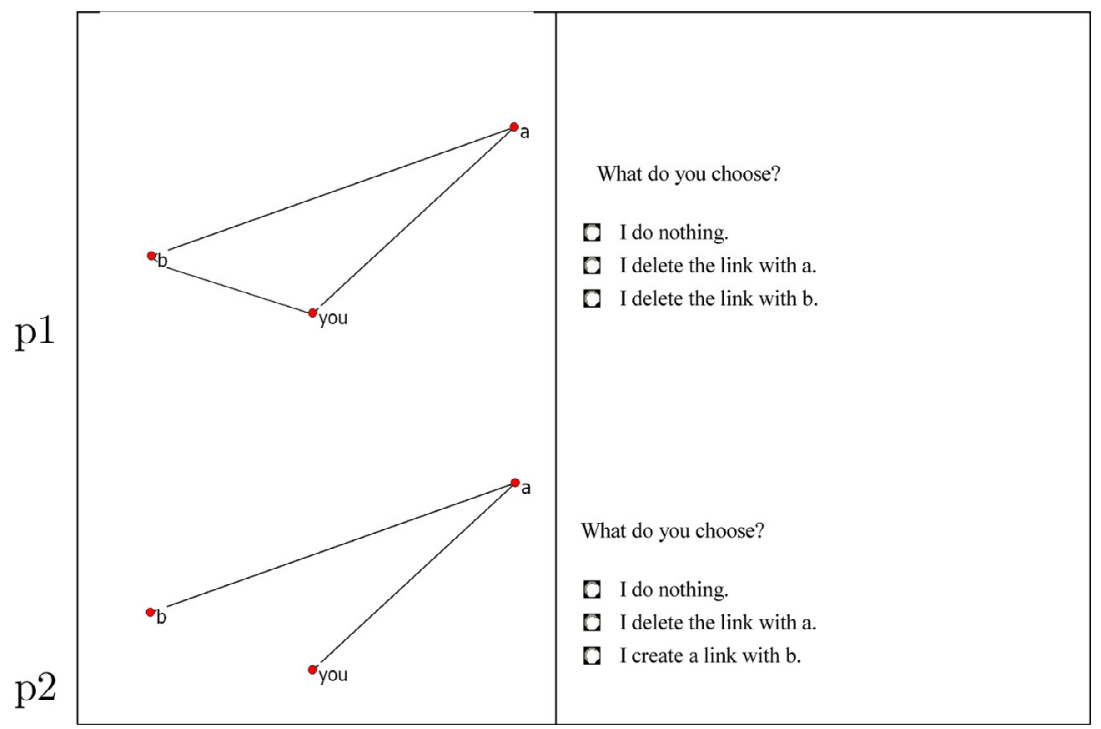


8. Difficulties were mentioned in the following fields: calculation: 33 , choice complexity: 35 , instructions: 26 , equivalent options: 5, none: 16 .

9. Further remarks: interesting/nice: 12, want to know more about the experiment: 10 , confirming what was said before: 5, suggestions: 10 .

10. Age: average 22.5 years, stand. dev.: 3.4 years.

11. Males: 48, females: 66 .

12. Dutch: 40, German: 43, Chinese: 9, other: 22.

13. Faculty of Economics \& Business Administration: 90, other: 24.

14. 90 participants did not participate in a similar experiment before; 24 did.

15. 112 participants would like to participate in future experiments, two would not.

16. In conditions social and both: 40 participants did not know any of their fellow session participants, 12 knew one and four knew more.

\section{Appendix C. Supplementary material}

Supplementary material (the experimental instructions) associated with this article can be found, in the online version, at 10.1016/j. ejor.2015.10.039

\section{References}

Bala, V., \& Goyal, S. (2000). A noncooperative model of network formation. Econometrica, 68(5), 1181-1229.

Baron, R., Durieu, J., Haller, H., \& Solal, P. (2006). Complexity and stochastic evolution of dyadic networks. Computers \& Operations Research, 33(2), 312-327.

Berkman, L. F., \& Syme, S. L. (1979). Social networks, host resistance, and mortality: a nine-year follow-up study of Alameda County residents. American Journal of Epidemiology, 109(2), 186-204.

Berninghaus, S. K., Ehrhart, K. M., \& Ott, M. (2006). A network experiment in continuous time: the influence of link costs. Experimental Economics, 9(3), 237-251.

Bonner, S. E. (1994). A model of the effects of audit task complexity. Accounting, Organizations and Society, 19(3), 213-234.

Broniarczyk, S. M., \& Alba, J. W. (1994). Theory versus data in prediction and correlation tasks. Organizational Behavior and Human Decision Processes, 57(1), 117-139.

Brown, M., Falk, A., \& Fehr, E. (2004). Relational contracts and the nature of market interactions. Econometrica, 72(3), 747-780.

Callander, S., \& Plott, C. R. (2005). Principles of network development and evolution: an experimental study. Journal of Public Economics, 89(8), 1469-1495.

Camerer, C. (1998). Bounded rationality in individual decision making. Experimental Economics, 1(2), 163-183.

Charness, G., Fréchette, G. R., \& Kagel, J. H. (2004). How robust is laboratory gift exchange? Experimental Economics, 7(2), 189-205.

Charness, G., \& Jackson, M. O. (2007). Group play in games and the role of consent in network formation. Journal of Economic Theory, 136(1), 417-445.

Corbae, D., \& Duffy, J. (2008). Experiments with network formation. Games and Economic Behavior, 64(1), 81-120.

Deck, C., \& Johnson, C. (2004). Link bidding in laboratory networks. Review of Economic Design, 8(4), 359-372.

Dellaert, B. G. C., Donkers, B., \& Van Soest, A. (2012). Complexity effects in choice experiment-based models. Journal of Marketing Research, 49(3), 424-434.

Demaine, E. D., Hajiaghayi, M., Mahini, H., \& Zadimoghaddam, M. (2012). The price of anarchy in network creation games. ACM Transactions on Algorithms, 8(2), 1-13. Article ID: 13

Di Cagno, D., \& Sciubba, E. (2010). Trust, trustworthiness and social networks: playing a trust game when networks are formed in the lab. Journal of Economic Behavior \& Organization, 75(2), 156-167.

van Dolder, D., \& Buskens, V. (2014). Individual choices in dynamic networks: an experiment on social preferences. PLoS One, 9(4), e92276.

Fabrikant, A., Luthra, A., Maneva, E., Papadimitriou, C. H., \& Shenker, S. (2003). On a network creation game. Proceedings of the Annual ACM Symposium on Principles of Distributed Computing, 22, 347-351.
Falk, A., \& Kosfeld, M. (2012). It's all about connections: evidence on network formation. Review of Network Economics, 11(3), 1-36. Article ID: 2

Fehr, E., \& Schmidt, K. M. (2003). Theories of fairness and reciprocity: evidence and economic applications. Advances in economics and econometrics: theory and applications, Eighth World Congress of the Econometric Society 1 (pp. 208-257). Cambridge, UK: Cambridge University Press.

Forbus, K. D. (1993). Qualitative process theory: twelve years after. Artificial Intelligence 59(1-2), 115-123.

Freeman, L. C. (1979). Centrality in social networks: conceptual clarification. Social Networks, 1(3), 215-239.

Gigerenzer, G., Todd, P. M., \& The ABC Research Group (1999). Simple heuristics that make us smart. Oxford, UK: Oxford University Press.

Goeree, J. K., Riedl, A., \& Ule, A. (2008). In search of stars: network formation among heterogeneous agents. Games and Economic Behavior, 67(2), 445-466.

Granovetter, M. (1995). Getting a job: a study of contacts and careers (2nd). Chicago, IL; London, UK: University of Chicago Press.

Gürerk, O., \& Selten, R. (2012). The effect of payoff tables on experimental oligopoly behavior. Experimental Economics, 15(3), 499-509.

Hämäläinen, R. P., Luoma, J., \& Saarinen, E. (2013). On the importance of behavioral operational research: the case of understanding and communicating about dynamic systems. European Journal of Operational Research, 228(3), 623-634.

Hauk, E., \& Nagel, R. (2001). Choice of partners in multiple two-person prisoner's dilemma games. Journal of Conflict Resolution, 45(6), 770-793.

Hellmann, T., \& Staudigl, M. (2014). Evolution of social networks. European Journal of Operational Research, 234(3), 583-596.

Hensher, D. A., Rose, J. M., \& Greene, W. H. (2005). Applied choice analysis: a primer. Cambridge, UK: Cambridge University Press.

Harmsen - van Hout, M. J. W., Herings, P. J. J., \& Dellaert, B. G. C. (2013). Communication network formation with link specificity and value transferability. European Journal of Operational Research, 229(1), 199-211.

Iacobucci, D., \& Hopkins, N. (1992). Modeling dyadic interactions and networks in marketing. Journal of Marketing Research, 29(1), 5-17.

Jackson, M. O., \& van den Nouweland, A. (2005). Strongly stable networks. Games and Economic Behavior, 51(2), 420-444.

Jackson, M. O., \& Wolinsky, A. (1996). A strategic model of social and economic networks. Journal of Economic Theory, 71(1), 44-74.

Janssen, R. H. P., \& Monsuur, H. (2012). Stable network topologies using the notion of covering. European Journal of Operational Research, 218(3), 755-763.

Kahneman, D., Knetsch, J. L., \& Thaler, R. H. (1991). Anomalies: the endowment effect, loss aversion, and status quo bias. Journal of Economic Perspectives, 5(1), 193-206.

Katz, M. L., \& Shapiro, C. (1985). Network externalities, competition, and compatibility. The American Economic Review, 75(3), 424-440.

Kirchsteiger, G., Niederle, M., \& Potters, J. (2005). Endogenizing market institutions: an experimental approach. European Economic Review, 49(7), 1827-1853.

Maddox, W. T., Bohil, C. J., \& Dodd, J. L. (2003). Linear transformations of the payoff matrix and decision criterion learning in perceptual categorization. Journal of Experimental Psychology, 29(6), 1174-1193.

McFadden, D. (2001). Economic choices. The American Economic Review, 91(3), 351-378

Mengel, F. (2011). Infrequent choice possibilities and reversal of status quo bias. In European Economic Association E' Econometric Society Parallel Meetings, Oslo, Norway.

Monsuur, H. (2007). Stable and emergent network topologies: a structural approach. European Journal of Operational Research, 183(1), 432-441.

Olaizola, N., \& Valenciano, F. (2014). Asymmetric flow networks. European Journal of Operational Research, 237(2), 566-579.

Salisbury, L. C., \& Feinberg, F. M. (2010). Alleviating the constant stochastic variance assumption in decision research: theory, measurement, and experimental test. Marketing Science, 29(1), 1-17.

Simon, H. A. (1956). Rational choice and the structure of the environment. Psychological Review, 63(2), 129-138.

Sundararajan, A. (2008). Local network effects and complex network structure. The B.E Journal of Theoretical Economics, 7(1), 1-37. Article ID: 46.

Sung, M. C., Johnson, J. E. V., \& Dror, I. E. (2009). Complexity as a guide to understanding decision bias: a contribution to the favorite-longshot bias debate. Journal of Behavioral Decision Making, 2(3), 318-337.

Swait, J., \& Adamowicz, W. (2001). The influence of task complexity on consumer choice: a latent class model of decision strategy switching. Journal of Consumer Research, 28(1), 135-148.

Timmermans, D. (1993). The impact of task complexity on information use in multiattribute decision making. Journal of Behavioral Decision Making, 6(2), 95-111.

Varian, H. R. (1992). Microeconomic analysis (3rd). London, UK; New York, NY: Norton.

Wellman, B., Salaff, J., Dimitrova, D., Garton, L., Gulia, M., \& Haythornthwaite, C. (1996). Computer networks as social networks: Collaborative work, telework, and virtual community. Annual Review of Sociology, 22(1), 213-238. 